\title{
A IMPORTÂNCIA DA LITERATURA DE AUTORAS NE- GRAS BRASILEIRAS NA LUTA ANTIRRACISTA
}

The importance of the literature of black brazilian authors in the anti-racist fight

La importancia de la literatura de autoras negras para la lucha antirracista

\section{Giselle Maria Santos de Araujo ${ }^{1}$}

\section{RESUMO}

Em 2019 e 2020, coordenamos dois projetos de Extensão que se voltavam à temática antirracista no Instituto Federal do Rio Grande do Sul - Campus Alvorada. Os projetos tiveram como base metodológica a análise da literatura de escritoras negras brasileiras. Este artigo é resultado de reflexões advindas com os projetos. Defendemos que há a construção de uma tradição literária feminina negra a partir da escrita de Carolina Maria de Jesus, esta antecedida por outras escritoras negras que lançaram a semente dessa tradição. Argumentamos que, a partir da escrita de Carolina, cria-se uma estética negra feminina que se baseia em quebrar o silenciamento imposto às mulheres pretas no nosso país. Nossa hipótese é que a escrita poderosa de escritoras negras brasileiras se apresenta como força motriz no combate ao racismo.

Palavras-chave: Literatura; Antirracismo; Escritoras negras; Projeto de extensão.

\footnotetext{
1 Mestra em Literatura Comparada e doutoranda em Letras Neolatinas pela UFRJ; Professora EBTT de Língua Portuguesa, Espanhol e Literatura do IFRS
} - Campus Alvorada. 


\section{ABSTRACT}

In 2019 and 2020, we've coordinated two Extension projects that focused on the anti-racist theme at Instituto Federal do Rio Grande do Sul - Campus Alvorada. The projects had as methodological basis the analysis of the literature of black Brazilian female writers. This article is the result of reflections coming from the projects on the importance of these women in the anti-racist fight. We argue that there is a black female literary tradition that started with the writing of Carolina Maria de Jesus, herself preceded by other black writers who sowed the seed of this tradition. We argue that, from Carolina's writing, a black feminine aesthetic is created that is based on breaking the silence imposed on black women in our country. Our hypothesis is that the powerful writing of black Brazilian women presents itself as a driving force in the fight against racism.

Keywords: Literature; Anti-racism; Black writers; Extension project.

\section{RESUMEN}

En 2019 y 2020 coordinamos dos proyectos de Extensión sobre la temática antirracista en Instituto Federal do Rio Grande do Sul - Campus Alvorada. La base metodológica de los proyectos se constituyó en la análisis de la literatura de escritoras negras brasilenas. Este artículo resulta de reflexiones venidas con estos proyectos. Defendemos que la construcción de una tradición literaria feminina negra en Brazil empieza con la escritura de Carolina Maria de Jesus, antecedida por otras escritoras negras que echaran la semilla de esta tradición. Argumentamos que a partir de la escritura de Carolina se crea una estética negra feminina que tiene como base romper el silencio impuesto a las mujeres negras en nuestro país. Nuestra hipótesis es que la escrita poderosa de escritoras negras brasilenas se presenta como fuerza motriz del combate al racismo.

Palabras clave: Literatura; Antirracismo; Escritoras negras; Proyecto de extensión. 


\title{
INTRODUÇÃO
}

Quero começar este artigo sobre a importância da literatura de autoras negras brasileiras na luta antirracista com a palavra de um professor, Paulo Freire:

\begin{abstract}
Dizer a palavra não é privilégio de alguns homens, mas direito de todos os homens. Precisamente por isto, ninguém pode dizer a palavra verdadeira sozinho, ou dizê-la para os outros, num ato de prescrição, com o qual rouba a palavra aos demais... Não é possível o diálogo entre os que negam aos demais o direito de dizer a palavra e os que se acham negados deste direito. É preciso primeiro que os que assim se encontram negados no direito primordial de dizer a palavra reconquistem esse direito, proibindo que este assalto desumanizante continue. (FREIRE, 1996, p. 77).
\end{abstract}

Dizer a palavra sempre foi um desafio para a população negra brasileira, fustigada pela escravização. Silenciar nossas vozes sempre significou nos invisibilizar e impor poder sobre nós. O silêncio imposto pela máscara escrava, que proibia os escravizados de comer a colheita, também tinha o propósito de manter o direito de dizer a palavra como privilégio somente de alguns.

A cidade de Alvorada possui a segunda maior taxa em homicídios de jovens negros do estado do Rio Grande do Sul, segundo o Atlas da Violência 2019, divulgado pelo Instituto de Pesquisa Econômica Aplicada (IPEA) e o Fórum Brasileiro de Segurança Pública (FBSP). Feita com base no Sistema de Informação sobre Mortalidade, do Ministério da Saúde, a pesquisa avaliou a violência no Brasil no ano de 2008 a 2018. Para a diretora executiva do FBSP e coordenadora da pesquisa, Samira Bueno, em entrevista à Agência Brasil,

um elemento central para a gente entender a violência letal no Brasil é a desigualdade racial. Se alguém tem alguma dúvida sobre o racismo no país, é só olhar os números da violência porque traduzem muito bem o racismo nosso de cada dia. (BUENO, 2020).

Essa violência que atinge mais fortemente a população negra se dá por conta do racismo estrutural que organiza nossa sociedade ${ }^{1}$. 


\section{OS PROJETOS DE EXTENSÃO "AUTORAS NEGRAS BRASILEI- RAS: LITERATURA PARA TER VOZ" E "TÓPICOS EM EDUCA- ÇÃO ANTIRRACISTA"}

O Campus Alvorada possui expressiva quantidade de alunos negros que têm demonstrado preocupação com essa realidade social que vivenciam. No entanto, muitos desses alunos desconheciam a força da literatura de autoria negra de nosso país no combate ao racismo, desconhecimento gerado pela invisibilidade imposta aos intelectuais negros, principalmente às escritoras mulheres negras $^{2}$.

O projeto “Autoras negras brasileiras: literatura para ter voz", realizado no ano de 2019, teve como objetivo, então, suprir essa lacuna.

Pela sua expressiva quantidade de alunos negros, o Campus Alvorada tem buscado desenvolver ações que conscientizem a população para a necessidade da redução das desigualdades étnico-raciais e para a valorização do negro no cenário social. Nesse sentido, a questão da mulher negra entra em pauta. Ocupando, em geral, posições subalternas e de pouca relevância social, a mulher negra foi/é, por vezes, silenciada e invisibilizada³ . A pesquisadora Jéssica Mara Raul (2016), ao analisar a questão das mulheres negras e a luta por igualdade, afirma que

os negros foram aprisionados na base da pirâmide social; e no caso das
mulheres negras - sujeitos da nossa análise - estas amargam, por seu
pertencimento étnico-racial e de gênero, os piores índices. Deste modo,
raça, gênero e classe podem explicar a manutenção das desigualdades
em relação às mulheres negras, na qual o acesso diferenciado à educação
e ao mercado de trabalho garantem sua manutenção. (RAUL, 2016, 292).

O projeto "Autoras" teve o propósito de refletir sobre questões relativas à mulher negra, à cultura e a relações étnico-raciais no Brasil a partir do resgate da literatura de autoria negra feminina. Além de atender ao público interno, o projeto atendeu também a população de Alvorada externa ao campus que se mostrou interessada em aprofundar a reflexão e o debate sobre essas questões.

\footnotetext{
${ }^{1}$ Sobre racismo estrutural e sua relação direta com a violência no Brasil, ver ALMEIDA, 2019.

${ }^{2}$ Sobre a invisibilidade imposta aos intelectuais negros no Brasil, ver DALCASTAGNÈ, 2005/2018. Disponível em https://revistacult.uol.com.br/home/ quem-e-e-sobre-o-que-escreve-o-autor-brasileiro/.

${ }^{3}$ Torna-se importante relacionar a invisibilidade das mulheres negras aos dados de homicídio de mulheres negras coletados pelo IPEA no Atlas da Violência 2018. Disponível em: https://www.ipea.gov.br/portal/images/stories/PDFs/relatorio_institucional/180604_atlas_da_violencia_2018.pdfArquivo consultado em 26 de abril de 2021.
} 
Em relação à literatura brasileira, verifica-se que as obras produzidas por autoras negras possuem pouco espaço editorial, sendo desconhecidas do público em geral e pouco estudadas nas escolas de educação básica e superior. Dessa forma, o projeto “Autoras" se propôs a dar visibilidade a essas escritoras e suas obras, discutindo as questões que permeiam suas produções artístico-literárias.

O projeto de extensão teve início no dia 17/04/2019 e finalizou no dia 10/09/2019, e realizou-se quinzenalmente às quartas-feiras, durando cada encontro um total de 2 horas, totalizando 20 horas de duração. Inicialmente, o horário era das 17:00 às 19:00hs, no entanto, diante de pedido de membros da comunidade externa ao campus, passamos a iniciar às 18:00hs, assim incluindo moradores de Alvorada que iam diretamente do trabalho para os encontros presenciais.

Apresentando, através de rodas de leitura quinzenais, a literatura feminina negra de resistência expressa na escrita poderosa de Carolina Maria de Jesus e de Conceição Evaristo, o projeto também aprofundou os conhecimentos da comunidade de Alvorada sobre feminismo e direitos das mulheres a partir do olhar crítico das teóricas feministas negras Angela Davis, bell hooks ${ }^{4}$ e Djamila Ribeiro.

O projeto teve como eixo metodológico a leitura das autoras negras brasileiras citadas, especificamente as obras literárias Quarto de Despejo: diário de uma favelada, livro de Carolina Maria de Jesus, cuja primeira publicação é de 1960, e Becos da memória, de Conceição Evaristo, obra do ano de 2006. As leituras literárias foram acompanhadas pelas leituras teóricas das obras Mulheres, raça e classe, da feminista norte-americana Angela Davis, O feminismo é para todo mundo: políticas arrebatadoras, da teórica social feminista negra bell hooks e Quem tem medo do feminismo negro, da filósofa negra brasileira Djamila Ribeiro. A dinâmica dos encontros obedecia a essa ordem: leitura orientada de textos escolhidos das obras literárias e teóricas citadas seguida de debates e discussões.

Os participantes se envolveram ativamente na construção do diálogo para a compreensão das questões étnico-raciais e de gênero, suscitadas pela leitura crítica das obras literárias. Nos dez encontros, tivemos uma média de participação de trinta pessoas, entre servidores e funcionários do campus, alunos tanto do Ensino Médio quanto do Proeja e seus familiares e professores da rede municipal de Alvorada.

A teórica Raquel Ortega (2020, p. 5) defende que a literatura, como força de liberdade, tem o poder de mobilizar saberes por meio da escrita, estabelecendo um diálogo entre os saberes pessoais

\footnotetext{
${ }^{4}$ A escritora faz questão de afirmar que bell hooks deve ser escrito em letra minúscula, representando seu desejo de dar destaque ao conteúdo de sua escrita e não à sua pessoa.
} 
e os saberes do texto literário. A relação de identificação entre os participantes do projeto, principalmente as participantes mulheres negras, e os textos de Carolina e Conceição se deu exatamente porque os relatos fizeram sentido para elas, o que favoreceu o interesse pela leitura mesmo diante da falta de experiência como leitoras. Como resultado, verificou-se ao longo do projeto que os participantes alcançaram um grande conhecimento sobre as obras em questão e sobre a vinculação das leituras realizadas à problemática do racismo em suas vidas cotidianas.

Participantes negros e negras relataram só se darem conta de que sofriam racismo em suas relações pessoais e em seus ambientes profissionais após a participação nas rodas de leitura. Professores e profissionais de educação relataram mudanças de posicionamento e a aplicação de práticas antirracistas em suas salas de aula a partir do conhecimento adquirido nos encontros do projeto. Houve relatos também de interesse pela leitura das autoras estudadas por familiares que não participaram do projeto "Autoras".

No ano de 2020, o interesse pelo projeto "Autoras" e pela leitura de escritoras negras brasileiras e a presença de professores da rede municipal de ensino de Alvorada no projeto suscitaram outros questionamentos. Perguntávamos se a escola, de certa forma, não reproduzia o racismo estrutural de nossa sociedade. Os professores presentes no projeto "Autoras" haviam relatado diversos momentos em que o racismo esteve presente em suas escolas, inclusive em suas práticas didáticas. Cientes de que o racismo afeta diretamente os estudantes negros, não só pela violência em si, mas também por suas consequências, como baixa autoestima, baixo rendimento escolar, segregação, sentimento de não-pertencimento e evasão, começamos a elaborar um segundo projeto de extensão, voltado a uma prática educativa antirracista.

Uma educação antirracista é aquela que permite que todos tenham sua identidade e história respeitadas e acolhidas no espaço escolar ${ }^{5}$. Para isso acontecer é racismo na escola deve ser combatido através de práticas educativas antirracistas.

Por isso, em 2020, desenvolvemos o Projeto de Extensão “Tópicos em necessário que gestores, funcionários, alunos e principalmente professores pensem e dialoguem em conjunto com as famílias, a comunidade, a sociedade civil, os estudantes e todos os profissionais de educação para compreender como o racismo se manifesta e para criar coletivamente um plano de ação para superá-lo. Sendo assim, o Educação Antirracista", tendo como público-alvo professores e profissionais de educação. Ancorados na Lei $n^{\circ} 10.639^{6}$, de 9 de janeiro de 2003, e tendo como campo disciplinar os Estudos afro-latino-americanos (Andrews, 2007; Gelado e Secreto, 2016; De la Fuente, 2018), discutiu-se temas e questões relativas ao racismo e à educação antirracista, tendo como ponto de partida, novamente, textos de literatura brasileira de escritoras negras. 
Os Estudos Afro-latino-americanos se desenvolvem em resposta e em paralelo a uma onda de movimentos políticos, culturais e sociais racialmente definidos que se deu nos anos 60 do século XX, principalmente os diversos Movimentos Negros que surgiram na região da América Latina e que problematizaram pontos que confluíam em toda a região: escravidão, relações raciais pós-escravidão, desigualdades raciais e a organização política dos afrodescendentes. Sendo assim, os Estudos afro-latino-americanos partem do histórico e do teórico, pois remapeiam as histórias, estratégias e lutas dos chamados negros da região desde o tráfico de escravos do Atlântico Sul até os movimentos identitários atuais, mas tendo a raça como variável-chave no processo de formação das nações latino-americanas. Nesse sentido, a agência dos afro-latino-americanos se constitui como perspectiva de análise também no campo das Artes, ainda que seja este um campo em construção, que inclui também o âmbito da Literatura e da Educação, bases nas quais se situa o nosso projeto.

Trabalhamos os seguintes tópicos no projeto de extensão “Tópicos em Educação Antirracista": diáspora negra, racismo estrutural, racismo institucional, racismo aversivo, racismo recreativo, apropriação cultural, colorismo, amor afrocentrado, empoderamento negro, intolerância religiosa, feminismo negro e interseccionalidade. O projeto começou no dia 24 de setembro de 2020 e foi realizado de forma integralmente online, por conta da pandemia da Covid-19 e a necessidade de distanciamento social. Uma semana antes, abrimos uma sala de aula no aplicativo Google Classroom e semanalmente disponibilizamos os materiais que seriam utilizados nos encontros online, que eram realizados uma vez por semana, com duração de 2 horas, pelo aplicativo Google Meet. O projeto totalizou vinte horas de duração e foi totalmente gratuito aos participantes.

O Projeto “Tópicos” contou com 82 participantes assíduos, sendo 73,8 \% professores das redes municipal e estadual. Em relação à região abarcada pelo projeto, $36 \%$ dos participantes foram das regiões de Alvorada e Porto Alegre. Mas tivemos também participantes dos estados do Rio de Janeiro, São Paulo, Mato Grosso, Paraíba, Bahia e Pernambuco, e também uma participante internacional, da Cidade do México.

O projeto teve como eixo metodológico a leitura, análise e discussão de textos literários escolhidos de autoras negras brasileiras e de textos teóricos de cientistas e pesquisadores, em sua maioria negros e latino-americanos, buscando, assim, apresentar aos participantes uma epistemo-

\footnotetext{
${ }^{5}$ BRASIL, Ministério da Educação/Secad. Diretrizes curriculares nacionais para a educação das relações étnico-raciais e para o ensino de história e cultura afro-brasileira e africana na educação básica. Brasília, DF, junho de 2005.

${ }^{6}$ BRASIL. LEI No 10.639, DE 9 DE JANEIRO DE 2003. Altera a Lei no 9.394, de 20 de dezembro de 1996, que estabelece as diretrizes e bases da educação nacional, para incluir no currículo oficial da Rede de Ensino a obrigatoriedade da temática "História e Cultura Afro-Brasileira", e dá outras providências.
} 
logia não eurocêntrica. Os participantes se envolveram ativamente na construção do diálogo para a compreensão tanto das questões relativas ao racismo e às questões étnico-raciais quanto de práticas educativas antirracistas. O projeto se assentou no tripé Ensino-Pesquisa-Extensão, já que se voltou ao público externo à instituição, tendo sua base no ensino de Literatura e é resultado de pesquisa acadêmica de membros da equipe executora.

Levamos conhecimento teórico aprofundado aos participantes a partir de leituras, análises e debates de conceitos como negritude, culturas do Atlântico Negro, heterogeneidade cultural, miscigenação, democracia racial, raça, racismo e educação antirracista. E apresentamos a literatura de escritoras negras brasileiras a partir de textos de Maria Firmina dos Reis, Carolina Maria de Jesus, Ruth Guimarães, Conceição Evaristo, Eliana Alves Cruz, Miriam Alves, Ana Maria Gonçalves, Adriana Ortega, Cidinha da Silva, Lia Vieira, Giselle Maria e Débora Garcia. Muitas destas autoras eram desconhecidas dos participantes, mesmo sendo estes em sua maioria professores, e após a leitura e análise de suas obras, participantes relataram que passaram a incluí-las na listagem da biblioteca de suas respectivas escolas e em seus planos de trabalho docente.

Os resultados que obtivemos com os projetos de extensão "Autoras negras brasileiras: literatura para ter voz" e "Tópicos em Educação antirracista" demonstrou que a literatura de escritoras negras brasileiras é uma força motriz para a construção de uma prática educativa antirracista. Diante disso, o presente artigo se debruça em mapear, ainda que de forma sintética, a tradição literária feminina negra no Brasil, considerando essa tradição essencial para o combate ao racismo em nosso país.

\section{A LITERATURA FEMININA NEGRA BRASILEIRA: MARIA FIR- MINA DOS REIS E RUTH GUIMARÃES}

Negra, maranhense, filha ilegítima de um homem negro com uma mulher branca, Maria Firmina dos Reis nasce em São Luís, em 1825, e reivindica o direito de dizer a palavra. Em pleno processo escravocrata no Brasil, que, lembrando, foi o último país do mundo a abolir a escravidão em 1888, Maria Firmina reivindica o direito de dizer a palavra através da literatura quando publica seu romance, Úrsula, em 1859. Assim diz Maria Firmina no prólogo de Úrsula (2018, p.18): 
Por que o publicas? Perguntará o leitor.

Como uma tentativa, e mais ainda, por este amor materno, que não tem limites, que tudo desculpa - os defeitos, os achaques, as deformidades do filho - e gosta de enfeitá-lo e aparecer com ele em toda a parte, mostrá-lo a todos os conhecidos e vê-lo mimado e acariciado.

Essas são palavras de nossa primeira romancista negra, autora do primeiro romance abolicionista brasileiro. Mostrar a palavra a todos sendo uma mulher negra professora, que ousou inclusive criar e manter, a despeito de toda a perseguição, uma escola mista de alfabetização para crianças negras e brancas, significava quebrar a máscara do silêncio que Maria certamente via nas fazendas da região ${ }^{7}$.

A pesquisadora Maria Helena Machado na introdução da edição de Úrsula que utilizamos neste trabalho afirma que

A decisão de Maria Firmina de publicar sua obra, de vê-la caminhando entre críticos e leitores, é, ao cabo, um ato de desafio e autoconfiança. Firmina quer ver Úrsula superando as barreiras, fazendo-as notar. (MACHADO, 2018, p.19)

Tal ato de desafio e de autoconfiança no seu direito de dizer a palavra se expressa em seu romance. Maria Firmino faz em Úrsula uma forte crítica ao patriarcado e à escravidão. E o faz com uma excelência narrativa que não deixa nada a desejar a um José de Alencar, como vemos no trecho de Úrsula abaixo:

Senhor Deus! Quando calará no peito do homem a tua sublime máxima - ama a teu próximo como a ti mesmo -, e deixará de oprimir com tão repreensível injustiça ao seu semelhante!... Àquele que também era livre no seu país. Àquele que é seu irmão?! E o mísero sofria; porque era es-

${ }^{7}$ Sobre Maria Firmina dos Reis e sua atuação como professora, ver MARIA HELENA MACHADO e FLÁVIO GOMES, 2019 , e MULLER, 2008. 
cravo, e a escravidão não lhe embrutecera a alma; porque os sentimentos generosos, que Deus lhe implantou no coração, permaneciam intactos, e puros como a sua alma. Era infeliz; mas era virtuoso. (REIS, 2018, p.54-55)

Entretanto, apesar da inegável qualidade literária da obra de Firmina e do seu ato de autoconfiança e desafio em falar, escrever, numa sociedade fechada a pessoas negras, não podemos dizer que Maria inaugura uma tradição literária porque sua obra, por motivos óbvios (baixa escolaridade dos negros no Brasil no século XIX), não teve o alcance necessário entre pessoas negras. A importância de Maria Firmina e sua literatura na luta antirracista é que a autora é uma antecedente, a primeira a romper com o silêncio imposto aos negros a partir da literatura.

Outra antecedente é a escritora negra Ruth Guimarães. Nascida em Cachoeira Paulista, SP, em 13 de junho de 1920, a professora Ruth, além de poeta, romancista, contista, cronista, jornalista e teatróloga, foi notória tradutora e pesquisadora da literatura oral no Brasil.

Aos dez anos já publicava versos nos jornais de Cachoeira Paulista. Aos dezoito anos, começa a estudar na USP, onde concluiu os cursos de Filosofia e, mais tarde, de Letras Clássicas. Como jornalista, colaborou na imprensa paulista e carioca, mantendo também por vários anos uma seção permanente de literatura nas páginas da Revista do Globo, de Porto Alegre, em que resenhava livros, mantinha um concurso de contos e onde publicou seus primeiros textos literários e traduções. Escreveu também crônicas e críticas literárias nas páginas de Correio Paulistano, A Gazeta, Diário de São Paulo, Folha de Manhã e Folha de São Paulo.

Quase 80 anos depois do romance de Maria Firmina, Ruth tem uma condição social muito diferente da maranhense e diferente da maioria das mulheres negras de sua época. Sua formação universitária e seu trabalho formal como jornalista davam a ela um destaque bem maior. Mas é como romancista que Guimarães consegue projeção nacional. Em 1946, ela publica Água funda, obra aplaudida por intelectuais de peso como Guimarães Rosa e Antonio Candido, este assina o prefácio da segunda edição. A escrita de Ruth é riquíssima, marcada por uma elegância literária e uma força expressiva notória:

O engenho é do tempo da escravatura. Seu Pedro Gomes, o morador mais antigo do lugar, ainda se lembra quando o paiol, perto da casa-grande, era senzala. Antes disso, era só um rancho de tropa, na baixada, 
e mato virgem subindo o morro. A casa-grande pode-se dizer que é de ontem. Tem pouco mais de cem anos e ainda dura outros cem. (...) O sol entra aqui, sem cerimônia, como gente de casa. Não adianta. Alguma coisa continua triste. Não há sol que espante os pensamentos da gente, num lugar vazio assim. (GUIMARÃES, 2018, p.18).

Pode-se dizer que Ruth Guimarães foi uma das primeiras escritoras negras a ocupar espaço nacional no cenário da literatura brasileira. Estudiosa da cultura popular, principalmente do folclore, e autora de diversas obras que valorizam essa vertente da nossa cultura, Ruth teve como mestre ninguém menos que Mário de Andrade. Segundo a escritora e pesquisadora, Mário foi o grande responsável por apresentá-la melhor ao folclore brasileiro. Além de Água Funda, lançou também Calidoscópio - A saga de Pedro Malazarte, Lendas e Fábulas do Brasil, Contos de Cidadezinha e o ensaio Os filhos do medo. Como tradutora, traduziu Balzac, Dostoievski, Daudet e Apuleio, além de ser autora de um importante dicionário da Mitologia Grega.

Entretanto, Ruth não conseguiu estabelecer uma tradição de escrita negra feminina no país. Sua obra caiu no gosto da academia, mas o fato de ser uma mulher negra escrevendo na mesma época de escritores como o próprio Guimarães Rosa fez com que seu nome caísse no ostracismo, a despeito da alta qualidade de sua escrita. Em 2007, reconhecendo esse silenciamento imposto à sua própria escrita negra, Ruth Guimarães declarou em entrevista ao Museu Afro-brasileiro: “Nós precisamos saber da raiz negra de onde viemos. A história negra está por fazer, a literatura negra está por fazer, a poesia está por fazer”.

São desses antecedentes que surge aquela que inaugurará uma tradição: Carolina Maria de Jesus.

\section{O ESTABELECIMENTO DE UMA TRADIÇÃO LITERÁRIA NE- GRA: CAROLINA MARIA DE JESUS}

Carolina Maria de Jesus nasceu em Sacramento, Minas Gerais, em 14 de março de 1914. Foi escritora, compositora e poetisa.

Carolina foi uma das primeiras escritoras negras do Brasil e é considerada uma das mais importantes escritoras do país. A autora viveu boa parte de sua vida na favela do Canindé, na Zona Norte de São Paulo, sustentando a si mesma e s a sua família como catadora de papéis. Ao mesmo 
tempo em que trabalhava como catadora, registrava o cotidiano da comunidade onde morava nos cadernos que encontrava no lixo. Um destes cadernos (somaram-se mais de vinte), um diário que havia começado em 1955, deu origem ao livro Quarto de Despejo: diário de uma favelada, que, com o auxílio do jornalista Audálio Dantas, foi publicado em 1960, cem anos depois da publicação de Úrsula.

A tradição que Carolina Maria de Jesus inaugura é a tradição da escrita de autoria feminina negra, principalmente pelo alcance que sua obra teve entre as pessoas negras. Quarto de despejo teve uma tiragem inicial de mil exemplares que se esgotou em uma semana. Desde sua publicação, a obra vendeu mais de um milhão de exemplares e foi traduzida para catorze línguas, tornando-se um dos livros brasileiros mais conhecidos no exterior.

Carolina, que só estudou até o antigo segundo ano primário, tem uma escrita sofisticada e de um vigor que rompe todo silêncio possível. Quando Carolina brada "Eu sou forte" ela não fala só de si, mas de toda a negritude da qual ela fazia parte. E a literatura para ela é força de vida.

A escritora Conceição Evaristo conta em relato para o site da UFMG ${ }^{8}$ sobre Literatura afro-brasileira que no Brasil

${ }^{8}$ Disponível em: http://www.letras.ufmg.br/literafro/autoras/188-conceicao-evaristo 
Essa tradição é a tradição de falar e se fazer ouvir. A escritora negra norte-americana Audre Lorde convocava a todas as mulheres negras no final dos anos 70 a quebrar o silêncio. Dizia ela em apresentação lida no painel sobre Lesbianismo e Literatura, da Associação de Língua Moderna, em Chicago, Illinois, em 28 de dezembro de 1977, que

\begin{abstract}
a transformação do silêncio em linguagem e em ação é um ato de auto-revelação, e isso sempre parece estar cheio de perigos (...) Neste país em que a diferença racial cria uma constante, ainda que não seja explícita, distorção da visão, as mulheres negras temos sido visíveis por um lado, enquanto que por outro nos fizeram invisíveis pela despersonalização do racismo (...) Tivemos que lutar, e seguimos lutando, para recuperar essa visibilidade que ao mesmo tempo nos faz mais vulneráveis: a de ser Negras (...) E essa visibilidade que nos faz tão vulneráveis, é também a fonte de nossa maior fortaleza. (LORDE, 1977, p.23)
\end{abstract}

Carolina Maria de Jesus quebrou o silêncio ao bradar a vizinhos, diante do jornalista Audélio Dantas. "Qualquer coisa ela dizia: 'Estou escrevendo um livro e vou colocar vocês lá'. Isso lhe dava autoridade", relatou certa vez Audélio. O jornalista, então, foi se inteirar e descobriu a poderosa escrita de Carolina, a simples catadora de papel. A denúncia social de Carolina, expressa em seus diários, é a voz negra quebrando o silêncio imposto a nós pelo racismo. Andre Lorde, afirma ainda que nós, pessoas negras, compartilhamos um compromisso com a linguagem e com o seu poder, e também com a recuperação da linguagem que foi utilizada contra nós. Ao transformar silêncio em linguagem e em ação, Carolina se torna vital para o estabelecimento de um necessário empoderamento porque subverte o poder estabelecido.

Joice Berth, em seu livro Empoderamento (2019), defende que o empoderamento é um instrumento de emancipação política e social que conduz indivíduos e grupos por diversos estágios de autoafirmação, autovalorização, autorreconhecimento e autoconhecimento de si mesmo e de suas mais variadas habilidades humanas e de sua história. Quando Carolina inaugura essa tradição de mulheres pretas escrevendo no Brasil, ela atua no empoderamento dos negros como grupo social, já que o termo tem por definição um caráter coletivo: ela leva os afrodescendentes brasileiros a se autoafirmarem como tais, a se autovalorizarem como negros, a se autoreconhecerem como etnia e a se autoconhecerem como um mesmo povo. 
Poderia trazer inúmeros trechos da literatura de Carolina para mostrar a efervescência literária dessa mulher preta. Escolho um poema presente em Antologia poética, livro publicado em 1996 depois de achados poéticos inéditos da autora. Minha escolha é o poema "Muitas fugiam ao me ver", no qual Carolina faz uma dura crítica à academia, pelo tratamento dado a ela como escritora, e ao racismo estrutural, que infelizmente se mantém em nossa sociedade:

\title{
MUITAS FUGIAM AO ME VER
}

\author{
Muitas fugiam ao me ver \\ Pensando que eu não percebia \\ Outras pediam pra ler \\ Os versos que eu escrevia
}

\author{
Era papel que eu catava \\ Para custear o meu viver \\ E no lixo eu encontrava livros para ler \\ Quantas coisas eu quiz fazer \\ Fui tolhida pelo preconceito \\ Se eu extinguir quero renascer \\ Num país que predomina o preto \\ Adeus! Adeus, eu vou morrer! \\ E deixo esses versos ao meu país \\ Se é que temos o direito de renascer \\ Quero um lugar, onde o preto é feliz.
}

Segundo a hispanista Raquel Ortega (2020), a literatura, como força de liberdade, tem o poder de mobilizar saberes por meio da escrita, estabelecendo um diálogo entre os saberes pessoais e os saberes do texto literário. A relação de identificação entre os textos de Carolina e os leitores negros, 
principalmente os leitores mulheres negras, se dá exatamente porque sua escrevivência, para usar um conceito de Conceição Evaristo, faz sentido para nós, o que favorece o interesse pela leitura mesmo diante da falta de experiência como leitor. Como resultado, os leitores conseguem vincular as leituras realizadas à problemática do racismo em suas vidas cotidianas, e, dessa forma, reagir a ele, assim como Carolina reagia: quebrando o silêncio, fazendo da palavra, da linguagem, uma autorrevelação e coragem.

Bebendo da fonte de Carolina, que instituiu uma tradição, surgem outras autoras negras, da qual destaco Conceição Evaristo.

\section{CONCEIÇÃO EVARISTO E A LITERATURA NEGRA FEMININA BRASILEIRA}

Maria da Conceição Evaristo de Brito nasceu em Belo Horizonte, em 1946, no ano de publicação de Água Funda. De família muito pobre, migrou para o Rio de Janeiro na década de 1970. Trabalhou como empregada doméstica até se formar em Letras na UFRJ e começar a trabalhar como professora da rede pública. É doutora em Literatura, pesquisadora da literatura negra.

Poeta, contista e ensaísta, Conceição só começa a publicar seus escritos aos 44 anos, na série Cadernos Negros, por conta do silenciamento que ainda tentam aplicar a escritoras negras que se assumem como tal. No prólogo da edição de 2018 de Becos da Memória, Evaristo (2018, p. 10) expõe esse silenciamento ao afirmar que

os originais de Becos da memória, a partir dessa e de outras frustradas publicações, ficaram esquecidos na gaveta (...) nas primeiras buscas por publicação, muitos caminhos foram incertos. (EVARISTO, 2018, 10).

Tanto que Evaristo só vem a publicar seu primeiro romance e ser reconhecida como escritora após os 70 anos, quando lança o romance Ponciá Vicêncio.

Com uma narrativa não-linear marcada por seguidos cortes temporais, em que passado e presente se imbricam, Ponciá Vicêncio teve boa acolhida de crítica e de público. O livro foi incluído nas listas de diversos vestibulares de universidades brasileiras e vem sendo objeto de artigos e dissertações acadêmicas.

Em 2006, Conceição Evaristo traz à luz seu segundo romance, Becos da memória, em que 
trata do drama de uma comunidade favelada em processo de remoção. E, mais uma vez, o protagonismo da ação cabe à figura feminina negra, símbolo de resistência à pobreza e à discriminação:

_ Menina, o mundo, a vida, tudo está aí! Nossa gente não tem conseguido quase nada. Todos aqueles que morreram sem se realizar, todos os negros escravizados de ontem, os supostamente livres de hoje, se libertam na vida de cada um de nós, que consegue se realizar. A sua vida, menina, não pode ser só sua. Muitos vão se libertar, vão se realizar por meio de você. Os gemidos estão sempre presentes. É preciso ter os ouvidos, os olhos e o coração abertos. (EVARISTO, 2017, p. 111)

Andre Lorde (1977, p. 25) vai dizer que se esperamos em silêncio que chegue a coragem para falar, o peso do silêncio vai nos afogar. Conceição, com sua escrita poderosa, nos ensina que a literatura escrita por mulheres negras é a força de que precisamos para quebrar o silêncio, para nos empoderar como grupo social oprimido e invisibilizado num país estruturalmente racista como o Brasil:

Sim, ela iria adiante. Um dia, agora ela já sabia qual seria a sua ferramenta, a escrita. Um dia, ela haveria de narrar, de fazer soar, de soltar as vozes, os murmúrios, os silêncios, o grito abafado que existia, que era de cada um e de todos. Maria-Nova um dia escreveria a fala de seu povo. (EVARISTO, 2017, p. 177)

Esse grito reverbera na literatura de mulheres negras que estão aí: Miriam Alves, Eliana Alves Cruz, Lia Vieira, Ana Maria Gonçalves, Cidinha da Silva, Débora Garcia, Mel Duarte, Fernanda Bastos, Adriana Ortega, Giselle Maria, todas nós bebemos das fontes daquelas vozes que mesmo emudecidas conservaram a voz. E nosso grito quebra a máscara, aponta o racismo e diz "ninguém mais nos calará”

Comecei com Paulo Freire e o trago novamente agora. Afirma o professor: 
A luta pela humanização (...) somente é possível porque a desumanização, mesmo que um fato concreto na história, não é, porém, destino dado, mas resultado de uma 'ordem' injusta que gera a violência dos opressores e esta, o ser menos. (...) O ser menos leva os oprimidos, cedo ou tarde, a lutar contra quem os fez menos. E esta luta somente tem sentido quando os oprimidos, ao buscarem recuperar sua humanidade, que é uma forma de criá-la, não se sintam opressores, nem se tornem, de fato, opressores dos opressores, mas restauradores da humanidade em ambos. E aí está a grande tarefa humanista e histórica dos oprimidos - libertar-se a si mesmos e aos opressores. (...) Só o poder que nasça da debilidade dos oprimidos será suficientemente forte para libertar a ambos. (FREIRE, 2012, p.30)

A literatura de Maria Firmina dos Reis, Ruth Guimarães, Carolina Maria de Jesus, Conceição Evaristo e todas que escreveram a partir de Carolina, é capaz de restaurar a humanidade de quem lê seus escritos. E humanidade e antirracismo andam lado a lado, são indispensáveis um ao outro. Por isso a importância da escrita de mulheres negras, que sempre foram oprimidas por nosso complexo corpo social: a literatura de autoria feminina negra é capaz de destruir opressões. Assim, finalizo com Carolina, aquela que inaugura a tradição literária feminina negra em nosso país, quando afirma na obra Meu estranho diário:

O livro... me fascina. Eu fui criada no mundo. Sem orientação materna. Mas os livros guiou os meus pensamentos. Evitando os abismos que encontramos na vida. Bendita as horas que passei lendo. Cheguei a conclusão que é o pobre quem deve ler. Porque o livro, é a bussola que ha de orientar o homem no porvir. (JESUS, 1996, p. 167)

\section{REFERENCIAS}

ALMEIDA, Silvio. Racismo Estrutural. São Paulo: Editora Jandaíra, 2019.

BERTH, Joice. Empoderamento. São Paulo: Pólen, 2019. 
DAVIS, Angela. Mulheres, raça e classe. Trad. Heci Regina Candiani. 1 ed. São Paulo: Boitempo, 2016

EVARISTO, Conceição. Becos da memória. 3 ed. Rio de Janeiro: Pallas, 2017.

FREIRE, Paulo. Pedagogia do Oprimido. São Paulo: Paz e Terra, 1996.

FREIRE, Paulo. Pedagogia do Oprimido. São Paulo: Paz e Terra, 2012.

GUIMARÃES, Ruth. Água funda. São Paulo: Editora 34, 2018, p. 18.

HOOKS, Bell. O feminismo é para todo mundo: políticas arrebatadoras. Trad. Ana Luíza Libânio. 2 ed. Rio de Janeiro: Rosa dos Tempos, 2018.

JESUS, Carolina Maria de. Antologia pessoal. Org. José Carlos Sebe Bom Meihy. Rio de Janeiro: Editora UFRJ, 1996.

JESUS, Carolina Maria de. Meu estranho diário. São Paulo: Xamã, 1996.

LORDE, Audre. Textos escolhidos de Audre Lorde. Disponível em: https://www.mpba.mp.br/ sites/default/files/biblioteca/direitos-humanos/direitos-da-populacao-lgbt/obras_digitalizadas/audre_lorde_-_textos_escolhidos_portu.pdf. Acessado em 19 de fevereiro de 2021.

ORTEGA, Raquel. "Prefácio”. In: MARIA, Giselle. Aula. 1 ed. Curitiba: Appris, 2020.

RAUL, Jéssica Mara. "Mulheres negras e a luta por igualdade: por um feminismo negro decolonial”. Revista Estudos de Sociologia. v. 21 n. 41 (2016): Dossiê: Colonialidade, Subalternidade e Identidades. 291-302.

REIS, Maria Firmina dos. Úrsula. São Paulo: 2018.

RIBEIRO, Djamila. Quem tem medo do feminismo negro?. 1 ed. São Paulo: Companhia das Letras, 2018. 